\title{
Consensus Management of Gastrointestinal Events Associated with Delayed-Release Dimethyl Fumarate: A Delphi Study
}

J. Theodore Phillips · April A. Erwin · Stephanie Agrella ·

Marcelo Kremenchutzky · John F. Kramer · Malcolm J. M. Darkes •

Jonathan Kendter $\cdot$ Heather Abourjaily $\cdot$ Jitesh Rana $\cdot$

Robert J. Fox

To view enhanced content go to www.neurologytherapy-open.com

Received: September 14, 2015 / Published online: November 2, 2015

(c) The Author(s) 2015. This article is published with open access at Springerlink.com

\section{ABSTRACT}

Introduction: Delayed-release dimethyl fumarate (DMF, also known as gastro-resistant DMF) is indicated for the treatment of patients with relapsing multiple sclerosis.

During completion of this work Dr. Rana was an employee of Biogen; he is now an employee of Genzyme.

Electronic supplementary material The online version of this article (doi:10.1007/s40120-015-0037-x) contains supplementary material, which is available to authorized users.

J. Theodore Phillips $(\bowtie)$

Baylor Institute for Immunology Research, Dallas, TX, USA

e-mail: j.theod.phillips@gmail.com

\section{A. A. Erwin}

NeuroMedical Center Clinic, Baton Rouge, LA, USA

S. Agrella

Multiple Sclerosis Clinic of Central Texas, Round

Rock, TX, USA

M. Kremenchutzky

Western University and London Health Sciences

Centre, London, Canada

J. F. Kramer

Center For Neurological Disorders, S.C., Milwaukee, WI, USA
Gastrointestinal (GI) adverse events (AEs) occur with DMF therapy.

Methods: We used a Delphi process to reach consensus among North American clinicians on effective real-world management strategies for GI AEs associated with DMF. Clinicians were asked to complete two rounds of questionnaires developed by a steering committee; consensus in round 2 was attained if $\geq 70 \%$ of respondents agreed on a particular strategy.

Results: Consensus was reached on several strategies to manage GI AEs, including administering DMF with food, slow titration, dose reduction, and use of symptomatic therapies.

M. J. M. Darkes

Excel Scientific Solutions, Horsham, UK

J. Kendter

Biogen, Weston, MA, USA

H. Abourjaily · J. Rana

Biogen, Cambridge, MA, USA

R. J. Fox

Mellen Center for Multiple Sclerosis, Cleveland Clinic, Cleveland, $\mathrm{OH}$, USA 
Conclusion: These consensus strategies provide clinicians with information on real-world approaches used to address the tolerability of DMF in patients with multiple sclerosis.

Funding: Biogen.

Keywords: Delayed-release dimethyl fumarate; Delphi technique; Disease management; Multiple sclerosis; Health care surveys

\section{INTRODUCTION}

Delayed-release dimethyl fumarate (DMF; also known as gastro-resistant DMF) $240 \mathrm{mg}$ twice daily is indicated for the treatment of patients with relapsing multiple sclerosis (MS) $[1,2]$. In two Phase III studies, DMF therapy met its primary endpoints by lowering the proportion of patients with a relapse [3] and annualized relapse rate [4] at 2 years. DMF demonstrated significant and sustained reductions versus placebo over 2 years across a range of clinical and magnetic resonance imaging outcome measures in the overall study population and across patient subgroups [5].

Based on the DMF safety profile in Phase III trials, which encompassed an overall drug exposure of 2244 person-years [1], gastrointestinal (GI) adverse events (AEs), particularly nausea, vomiting, abdominal pain, and diarrhea, were more common in the DMF group than the placebo group (40\% versus $31 \%$, respectively) $[3,4,6]$. In most cases, GI AEs were mild or moderate in severity, and occurred most frequently in the first month of treatment before decreasing thereafter [3, 4]. Phase III study protocols permitted ad hoc measures to optimize DMF tolerability, such as coadministration with food, symptomatic therapies, and dose reduction.

Because there is no best practice guiding the management of DMF-associated GI AEs, patients troubled by GI tolerability may become nonadherent and thus decrease their chance for maximally effective treatment outcomes [7]. Therefore, we used a Delphi consensus-building method to gain insights from experienced practitioners who prescribe DMF regularly in a real-world setting to manage MS in their patients. The Delphi survey was designed to capture the most effective strategies to manage GI AEs and therefore set appropriate expectations for affected patients.

\section{METHODS}

This survey-based consensus process focused on agreements with a series of questions relating to DMF-associated GI AEs using the Delphi technique, a widely accepted method of data collection that utilizes iterative rounds of data-gathering and hypothesis-testing questionnaires to build expert consensus on an issue $[8,9]$. By enabling identification of a rank-ordered cluster of answers from anonymous respondents that reflects group consensus on a particular question, the Delphi process mitigates the influence a few strong voices may have in the group $[8,9]$.

Our Delphi process was initiated in 2013 when a steering committee of six clinicians with considerable experience prescribing DMF was convened to develop two rounds of questionnaires and interpret the tabulated results. The outcome of the meeting yielded the first round of a formal Delphi survey featuring closed- and open-ended questions (see Fig. S1a for questionnaire structure) that focused on the following objectives: (1) to better understand the real-world incidence, characteristics, and impact of GI AEs associated with DMF; (2) to achieve consensus on strategies to manage GI AEs associated with 
DMF; and (3) to achieve consensus on how to best set patient expectations for the management of GI AEs associated with DMF.

Two hundred clinicians highly experienced in prescribing DMF for MS in the United States and Canada were invited to complete the first questionnaire and provide relevant demographic information through a Web-based survey tool (Survey Monkey ${ }^{\circledR}$, http://www.surveymonkey.com). The participants were selected as those with the highest number of patients currently receiving DMF, irrespective of treatment discontinuations, as recorded between March 23 and December 12, 2013 , in a proprietary database of prescription claims data (Biogen, data on file); participants were offered compensation for their time.

Respondents completing the questionnaire were asked to base their answers on the experience of a typical patient (i.e., their respective clinical population as an aggregate). Respondents with patients who had reported severe AEs (i.e., symptoms that cause severe discomfort, incapacitation, or have a significant impact on the patient's daily life; severity may cause cessation of treatment; treatment for symptoms may be given, and/or the patient may be hospitalized) also were asked the same or similar questions based on their most severe case(s). Furthermore, for both typical and severe cases, many of the questions were repeated for instances of each GI symptom, i.e., nausea, vomiting, abdominal pain, and diarrhea.

Respondents were encouraged to be as detailed as possible, where applicable, and to review charts and records to assist information recall. Respondents used their clinical judgment when answering questions and were not referred to any $\mathrm{AE}$ definitions other than those provided as part of the questions. All responses were aggregated to maintain responder anonymity. As is typical for Delphi surveys, no ethics review was necessary since data were regarding clinician opinion and no specific patient data (including patient identifiers) were collected. This article does not contain any new studies with human or animal subjects performed by any of the authors.

Results from closed-ended questions were presented descriptively (e.g., percentages, means, medians). The number of respondents to whom each question applied was used as the denominator. Open-ended responses were treated as qualitative data and, where possible, coded into categories.

Results from the first questionnaire were used to develop a 170-item second questionnaire (see Fig. S1b for questionnaire structure). As is typical for the Delphi process, results from the first questionnaire were provided along with the second questionnaire in the second round in an effort to obtain consensus on the management of each specific GI event. The second round questionnaire was issued, completed, and analyzed similar to the first round questionnaire. The criterion signifying achievement of consensus on the most effective methods to manage DMF-associated GI AEs in a clinical setting was agreed on by participants answering the first questionnaire and defined as a response score $\geq 70 \%$.

\section{RESULTS}

The first questionnaire was completed by 64 of 200 clinician invitees representing 58 clinical practice sites, and of these 64 respondents, 57 completed the second questionnaire. Most of the 64 clinicians were medical doctors (80\%), followed by nurse practitioners or physician assistants (19\%; Table S1). Most practiced in the United States $(88 \%)$, and had done so for $>10$ years $(72 \%$; Table $S 1)$. 
Nearly all respondents in the first (63/64) and second (56/57) questionnaire rounds stated that $\geq 1$ of their patients had experienced a GI AE with DMF. In the second round, 54 of 56 (96\%) respondents stated that $\geq 1$ of their patients had experienced a severe GI AE with DMF. The reported duration of most mild to moderate AEs was variable, although vomiting was the most likely of any $\mathrm{AE}$ to be relatively short lived and lasting $<2 \mathrm{~h}$ (Fig. S2). Compared with responses for each corresponding mild to moderate $\mathrm{AE}$, larger proportions of severe cases were thought to experience GI AEs for a longer duration, or continuously. Most respondents (51/56; 91\%) reported $\geq 1$ patient who experienced vomiting during treatment with DMF, and almost all respondents indicated that vomiting was preceded by nausea or abdominal pain, both in typical patients and severe cases.

Consensus was reached (55/56 respondents; 98\% agreement) that taking DMF with food is generally a useful management strategy to recommend to patients to reduce the incidence and/or severity of GI AEs. More specifically, consensus was reached that taking DMF with food was useful for nausea (98\%), vomiting (89\%), and abdominal pain (93\%), but not diarrhea (69\%). All respondents recommended food as a management strategy for any patient being treated with DMF, and 53 of $56(95 \%)$ respondents recommended food as a management strategy to all patients when they initiate treatment with DMF (Fig. 1). Similar percentages of respondents recommended food as a management strategy in typical patients with mild to moderate GI AEs (53/54; 98\%) or severe GI AEs (52/54; 96\%). Most respondents $(46 / 56 ; 82 \%)$ indicated that each of the mentioned food-based management strategies (e.g., high fat, high protein, low starch) could be helpful in reducing the impact of GI AEs with DMF therapy. High-fat meals (e.g., peanut butter) were the most frequent food-based recommendation in both typical and severe cases (Fig. S3).

Respondents agreed $(49 / 56 ; 88 \%)$ that a slower dose titration (i.e., $>7$ days to reach the approved maintenance dose of $240 \mathrm{mg}$ twice daily) of DMF than recommended in the prescribing information [1] was a useful management strategy for reducing the incidence and/or severity of GI AEs. Information on experience with titration strategies is given in Fig. 2. Slower titration was thought to be effective for reducing the incidence and/or severity of nausea (98\%), vomiting (96\%), abdominal pain (94\%), and diarrhea (92\%). All but 1 of 56 (98\%) respondents had used slower titration to reduce the incidence and/or severity of any or all GI AEs, and of these 55 respondents, 48 $(87 \%)$ had used slower titration in at least some patients (Fig. 2). The majority titrated DMF over a period $\leq 4$ weeks.

Temporary dose reduction also was considered a useful management strategy to reduce the impact of GI AEs in patients taking the approved dosage of DMF $240 \mathrm{mg}$ twice daily (49/56 respondents; $88 \%$ ); temporary DMF dose reduction was considered a useful management strategy for reducing the impact of nausea (100\%), vomiting (90\%), abdominal pain (90\%), and diarrhea (86\%). Fifty-two of 56 (93\%) respondents had attempted temporary dose reduction in patients with troublesome GI AEs, and of these respondents, 47 (90\%) found the strategy to be effective for reducing the incidence and/or severity of GI AEs. Most had used a dose of $120 \mathrm{mg}$ twice daily for 1-2 weeks, then retitrated using a slower titration period than that stated in the prescribing information (i.e., $\leq 4$ weeks; Fig. 3) [1]. Further information on the length of the dose reduction and influencing factors are summarized in Figure S4. 


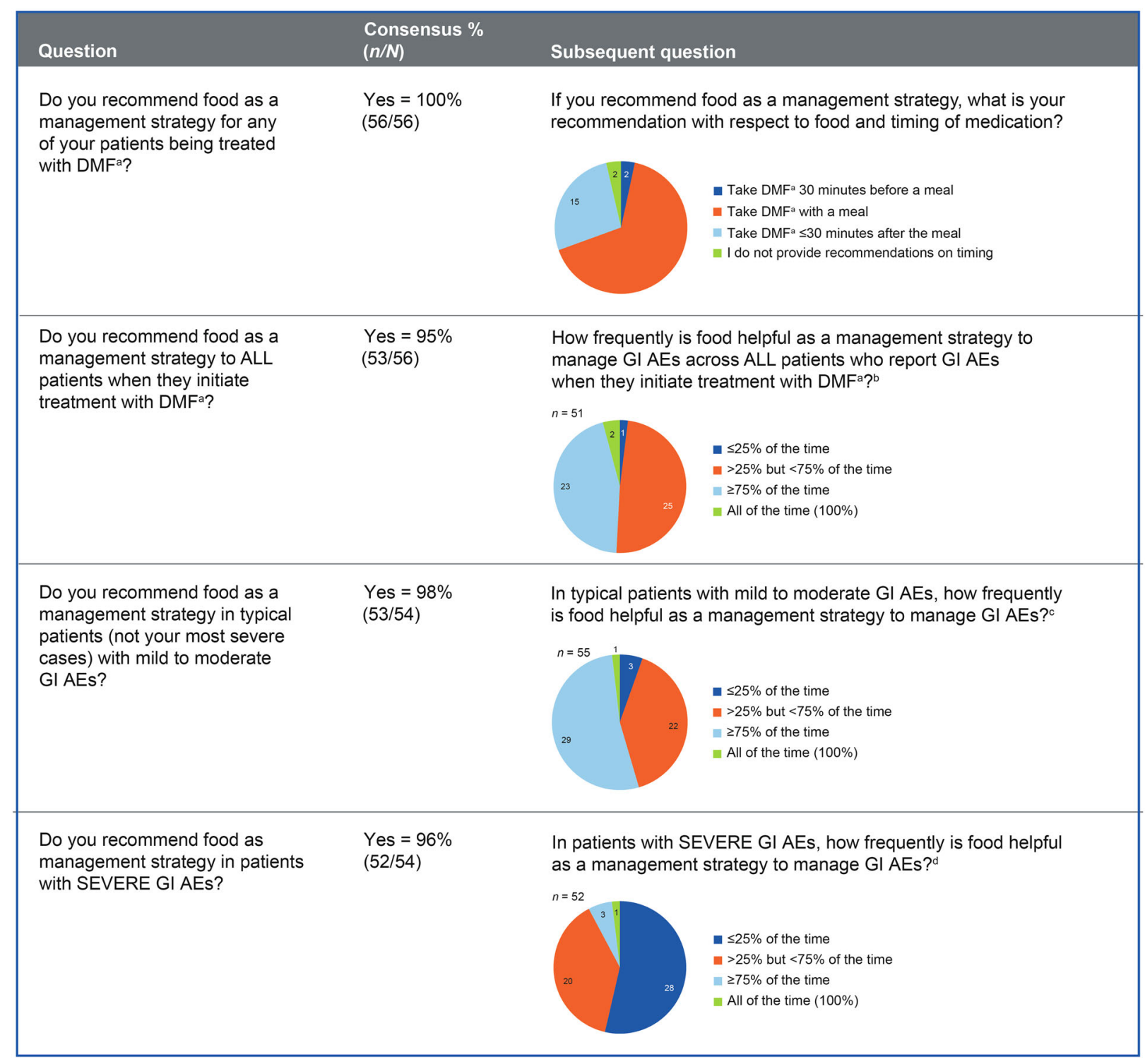

Fig. 1 Using food as a management strategy. a $\mathrm{DMF}=$ delayed-release dimethyl fumarate (also known as gastro-resistant DMF). b Question posed only to respondents with both typical patients and severe cases who reported food-based strategies as helpful. c Question

Consensus was achieved on the use of certain symptomatic therapies to alleviate GI AEs (Fig. 4). Most respondents (52/56; 93\%) agreed that ondansetron is a useful management strategy to consider for reducing the impact of nausea and vomiting. Slightly more than $70 \%$ of the respondents agreed that posed to all respondents who reported food-based strategies as helpful. d Question posed only to respondents who recommended food-based strategies for severe cases. $A E$ adverse event, $G I$ gastrointestinal

bismuth subsalicylate and promethazine have utility for managing both nausea and vomiting, as does use of antacids for nausea. It was agreed that abdominal pain can be managed with bismuth subsalicylate, antacids, and antisecretory drug treatment, while diarrhea can be managed with loperamide and 


\begin{tabular}{|c|c|c|}
\hline $\begin{array}{l}\text { Question (to respondents who } \\
\text { had used slower titration) }\end{array}$ & $\begin{array}{l}\text { Consensus \% } \\
(n / N)\end{array}$ & Subsequent question \\
\hline $\begin{array}{l}\text { Have you used slower titration } \\
\text { ( }>7 \text { days to reach the approved } \\
\text { maintenance dose of } 240 \mathrm{mg} \text { BID) } \\
\text { during initiation of treatment with } \\
\text { DMFa to reduce the incidence } \\
\text { and/or severity of any or all GI AEs? }\end{array}$ & $\begin{array}{l}\text { Yes }=98 \% \\
(55 / 56)\end{array}$ & 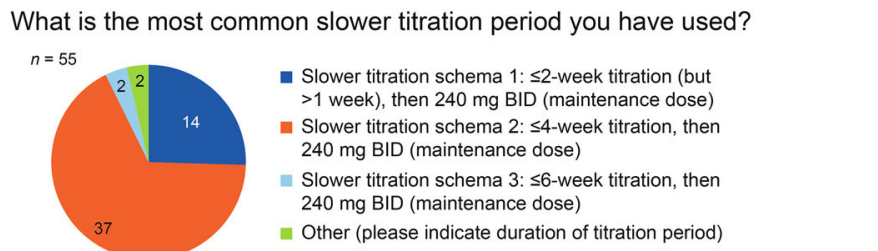 \\
\hline $\begin{array}{l}\text { Have you found the slower } \\
\text { titration schema helpful compared } \\
\text { with the recommended titration } \\
\text { of } 120 \mathrm{mg} \text { BID for } 7 \text { days (per } \\
\text { prescribing information) for } \\
\text { reducing the incidence and/or } \\
\text { severity of GI AEs in at least some } \\
\text { of your patients? }\end{array}$ & $\begin{array}{l}\text { Yes }=87 \% \\
(48 / 55)^{b}\end{array}$ & 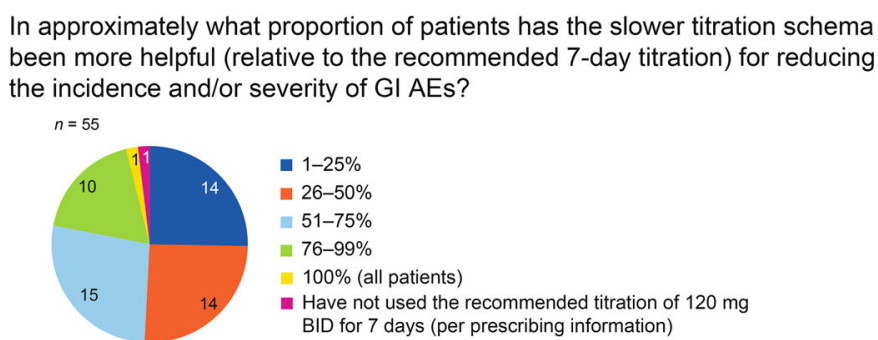 \\
\hline
\end{tabular}

Fig. 2 Slower dose titration as a management strategy. a $\mathrm{DMF}=$ delayed-release dimethyl fumarate (also known as gastro-resistant DMF). b One respondent had not used

diphenoxylate/atropine. Medications that appeared to not work (based on lack of agreement) were: for nausea, dimenhydrinate, histamine $\mathrm{H}_{2}$-receptor antagonists, metoclopramide, proton pump inhibitors, and prochlorperazine; for vomiting, dimenhydrinate, metoclopramide, and prochlorperazine; for abdominal pain, dicyclomine, simethicone, and sucralfate; and for diarrhea, bismuth subsalicylate (Fig. S5).

A causative relationship between the occurrence of GI AEs and discontinuation of DMF therapy was observed by 53 of 56 (95\%) respondents; however, $70 \%$ indicated that as management strategies have evolved over time and with increased experience using DMF, overall discontinuation rates due to GI AEs have decreased. All but 1 respondent (55/56; 98\%) agreed that patients should be provided with information on the potential for GI AEs (e.g., occurrence, impact) when starting treatment; in response to a separate question, the recommended titration of $120 \mathrm{mg}$ BID for 7 days. $A E$ adverse event, $B I D$ twice daily, GI gastrointestinal

49 of $56(88 \%)$ respondents agreed this information should be provided when the patient reports GI AEs. While there was agreement on both approaches, the responses suggest that providing information when starting treatment is the preferred option. All respondents agreed that at the time DMF therapy is initiated, health care providers should provide patients with information on management strategies for potential GI AEs. Forty-nine of 56 (88\%) respondents agreed that health care providers should supply patients with specific recommendations to manage potential GI AEs when treatment is initiated, and 51 of 56 (91\%) agreed this information should be provided when the patient reports GI AEs.

\section{DISCUSSION}

GI AEs, although reported to be mostly mild to moderate in severity in Phase II and III studies, 


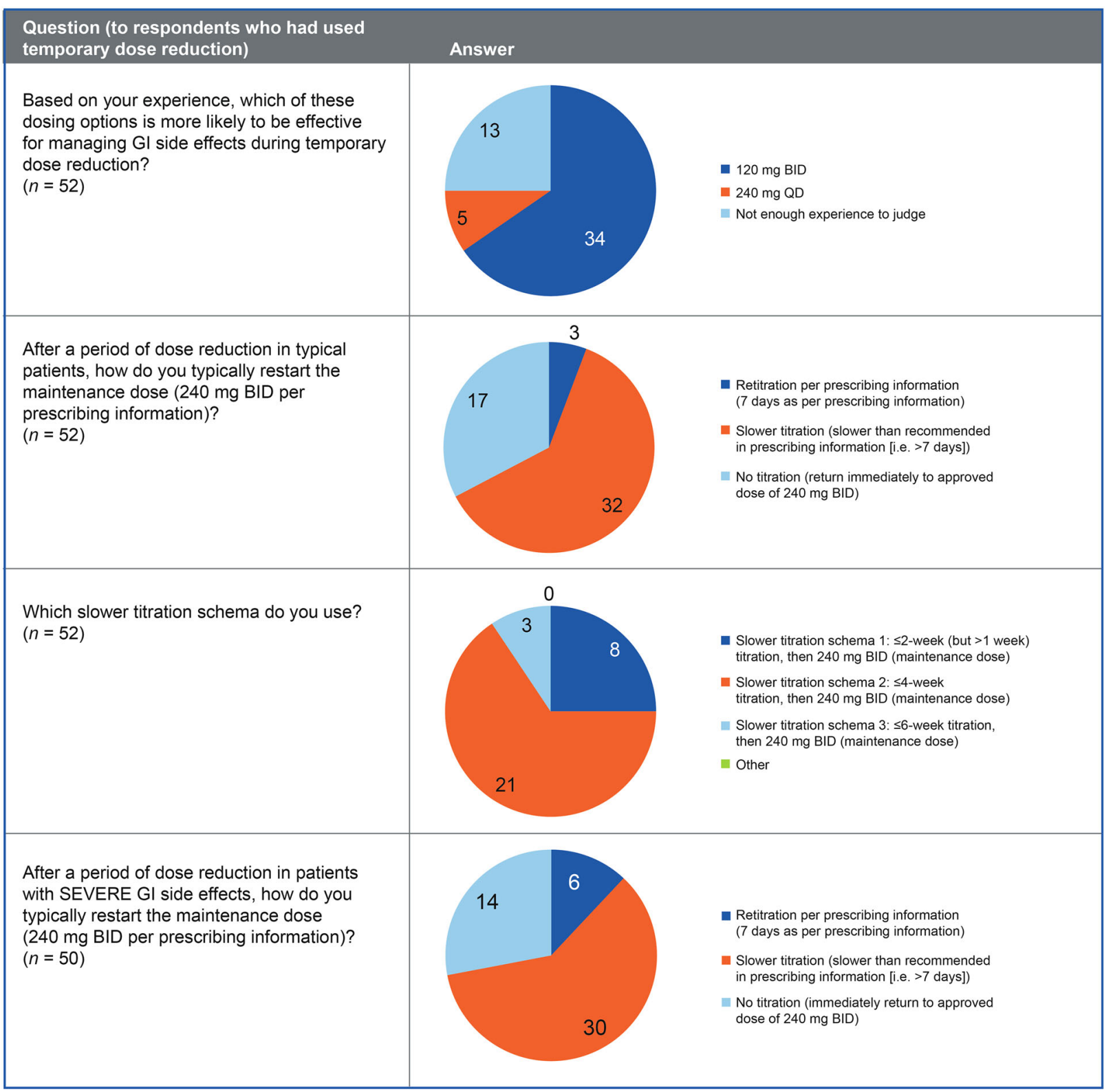

Fig. 3 Experience with a temporary dosage reduction. $B I D$ twice daily, $G I$ gastrointestinal, $Q D$ once daily

are experienced by a significant proportion of patients receiving DMF. Using a Delphi technique, we reached consensus on several potentially useful strategies to manage nausea, vomiting, abdominal pain, and diarrhea when using DMF, namely coadministration with food (particularly a high-fat meal such as peanut butter, yogurt, and cheese), dose titration $\leq 4$ weeks when initiating DMF therapy, temporary dose reduction to $120 \mathrm{mg}$ twice daily for 2-4 weeks, and use of specific symptom-directed therapies.

Furthermore, results from this Delphi panel suggest that use of such management strategies may reduce the likelihood of discontinuation of DMF due to GI AEs, which may in turn improve 


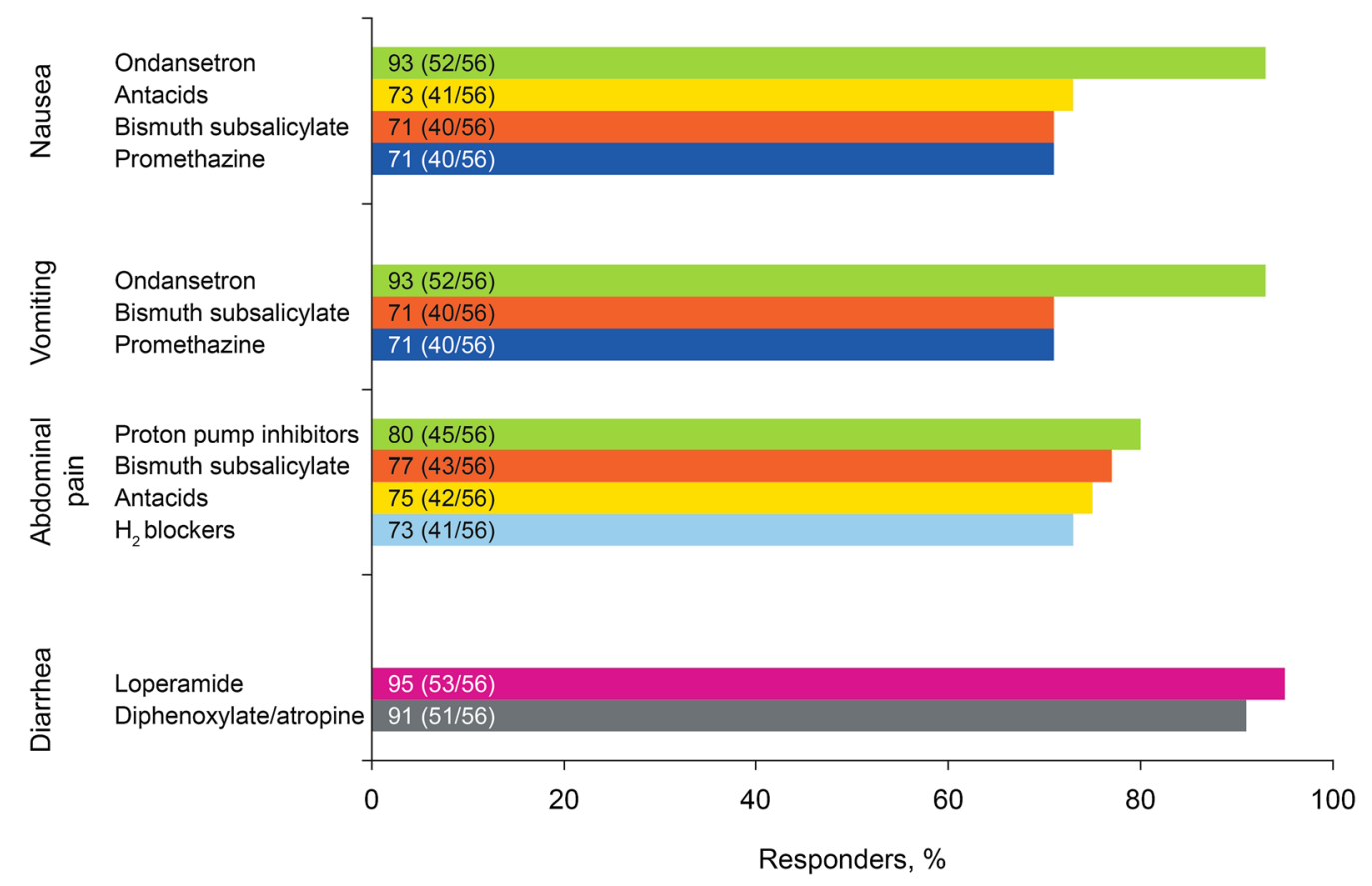

Fig. 4 Symptomatic therapies agreed to be useful in the management of each gastrointestinal adverse event

treatment outcome of this agent. Participants agreed that patient expectations can be managed more effectively by providing information on the potential occurrence and likely impact of GI AEs, and how these AEs can be managed when treatment with DMF is initiated. These outcomes are consistent with the guidelines of a 2009 consensus panel that conducted a systematic review of all disease-modifying agents for MS at the time and stressed the importance of good clinician-patient dialog to improve the quality of use of these medications [10]. A concordant relationship between prescriber and patient in which the patient is an active participant in the partnership is likely the best way to identify and manage patient concerns regarding medication use in light of the fluctuating disease course exhibited by MS. The importance of both patient and prescriber education on the management of GI AEs was highlighted by a previous survey regarding the management of GI AEs from a clinical trial population [11].
Our study had some strengths and some weaknesses. Key study attributes were the inclusion of health care professionals based on their high level of experience using DMF and whose number $(n=56)$ far exceeded that initially suggested and tested for such surveys to obtain consensus $(n=15-30)[8,9,12]$. Selection via an online clinician questionnaire was considered to be the most efficient method to obtain consensus on the effective management of GI AEs associated with DMF use. A study limitation was that clinicians assigned diagnoses and severity to symptoms using their best clinical judgment, and it is possible that there were practice gradients within these criteria. In addition, the scope of our analysis did not extend to ascertaining all factors involved in DMF-associated GI AEs among their patients, which likely involve a combination of specific effects such as MS disease and comorbidity burden. Thus, the study provides new data on GI AEs associated with DMF together with other contributory 
factors, rather than data on the effect of DMF alone. Of note, this study focused solely on GI AEs and did not intend to address any other common or uncommonly reported AEs [1, 2]. Because all the data presented in this cross-sectional study come from the experience of respondents and not solely on chart review, its accuracy may be limited by recall bias. Further, while the overall sample is representative of practice in the United States and Canada, it may not be reflective of practice in other developed countries. Finally, it should be noted that the reported data represent consensus obtained through the Delphi process and in no form constitute a clinical practice guideline that can only be developed using information from a broader range of sources, with categorized levels of evidence.

\section{CONCLUSION}

In conclusion, clinicians with experience using DMF reached consensus on several potentially useful real-world strategies to manage GI AEs, including administering DMF with food, slower titration, and use of symptomatic therapies. These strategies would benefit from formal evaluation in a prospective study. In the meantime, they may serve as useful options for clinicians to consider when managing GI AEs in their patients with MS who are receiving DMF therapy.

\section{ACKNOWLEDGMENTS}

The authors thank all the clinicians who completed the questionnaires. This study was supported by Biogen (Cambridge, MA, USA). The article processing charges for this publication were funded by Biogen. Biogen provided funding for medical writing support in the development of this manuscript. Malcolm J. M. Darkes (Excel Scientific Solutions, Horsham, UK) wrote the first draft of the manuscript based on input from authors, and Elizabeth Cassell (Excel Scientific Solutions, Southport, CT, USA) copyedited and styled the manuscript per journal requirements. Analyses were performed by Ed Parr and Alison Gagnon (Excel Scientific Solutions, Southport, CT, USA) and Becky Gardner (Excel Scientific Solutions, Horsham, UK) also assisted with the preparation of the manuscript. Biogen reviewed and provided feedback on the paper. The authors had full editorial control of the paper, and provided their final approval of all content. All named authors meet the International Committee of Medical Journal Editors (ICMJE) criteria for authorship for this manuscript, take responsibility for the integrity of the work as a whole, and have given final approval to the version to be published.

Disclosures. J. Theodore Phillips has received consulting fees from Acorda, Biogen, Genzyme, Merck Serono, and Sanofi-Aventis; and research support from Roche. April A. Erwin has served on advisory boards/speaker bureaus for Biogen and Novartis. Stephanie Agrella has received consulting fees from Acorda, Biogen, Genzyme, Pfizer, Serono, and Teva. Marcelo Kremenchutzky has received consulting fees and research support from Bayer HealthCare, Biogen, Genzyme, Novartis, Sanofi-Aventis, Serono, and Teva. John F. Kramer has received consulting fees from Biogen, Genzyme, Novartis, and Teva; research support from Biogen, Genzyme, and Novartis; and holds stock in Biogen. Jonathan Kendter is an employee of and holds stock/stock options in Biogen. Heather Abourjaily is an employee of and holds stock/stock options in Biogen. Jitesh Rana is an employee of and holds stock/stock 
options in Biogen. Robert J. Fox has received consulting fees from and served on advisory boards for Actelion, Biogen, MedDay, Novartis, Questcor, Teva, and Xenoport; and has received research support from Novartis.

Compliance with ethics guidelines. This article does not contain any new studies with human or animal subjects performed by any of the authors.

Open Access. This article is distributed under the terms of the Creative Commons Attribution-NonCommercial 4.0 International License (http://creativecommons.org/licenses/ by-nc/4.0/), which permits any noncommercial use, distribution, and reproduction in any medium, provided you give appropriate credit to the original author(s) and the source, provide a link to the Creative Commons license, and indicate if changes were made.

\section{REFERENCES}

1. Tecfidera (prescribing information). http://www. tecfidera.com/pdfs/full-prescribing-info.pdf. Accessed 27 April 2015.

2. European Medicines Agency. Tecfidera summary of product characteristics. http://www.ema.europa. eu/docs/en_GB/document_library/EPAR_-_ Product_Information/human/002601/ WC500162069.pdf. Accessed 27 April 2015.

3. Gold R, Kappos L, Arnold DL, DEFINE Study Investigators, et al. Placebo-controlled phase 3 study of oral BG-12 for relapsing multiple sclerosis. N Engl J Med. 2012;367:1098-107.
4. Fox RJ, Miller DH, Phillips JT, CONFIRM Study Investigators, et al. Placebo-controlled phase 3 study of oral BG-12 or glatiramer in multiple sclerosis. N Engl J Med. 2012;367:1087-97.

5. Viglietta V, Miller D, Bar-Or A, et al. Efficacy of delayed-release dimethyl fumarate in relapsing-remitting multiple sclerosis: integrated analysis of the phase 3 trials. Ann Clin Transl Neurol. 2015;2:103-18.

6. Meltzer L, Selmaj K, Gold R, et al. Gastrointestinal tolerability events in relapsing-remitting multiple sclerosis patients treated with BG-12 (dimethyl fumarate) in DEFINE and CONFIRM. Neurology. 2013;80(meeting abstracts 1):P01.164.

7. Devonshire V, Lapierre Y, Macdonell R, et al. GAP Study Group. The Global Adherence Project (GAP): a multicenter observational study on adherence to disease-modifying therapies in patients with relapsing-remitting multiple sclerosis. Eur J Neurol. 2011;18:69-77.

8. Hsu C-C, Sandford B. The Delphi technique: making sense of consensus. Pract Assess Res Eval [serial online] 2007;12:1-8. http://pareonline.net/ getvn.asp?v=12\&n=10. Accessed 27 April 2015.

9. Delbecq A, Van de Ven AH, Gustafson DH. The Delphi technique. In: Delbecq A, Van de Ven AH, Gustafson DH. Group techniques for program planning: a guide to nominal group and Delphi processes. Glenview, IL: Scott, Forseman, and Company; 1975.

10. Brandes DW, Callender T, Lathi E, O'Leary S. A review of disease-modifying therapies for MS: maximizing adherence and minimizing adverse events. Curr Med Res Opin. 2009;25:77-92.

11. Phillips JT, Hutchinson M, Fox R, Gold R, Havrdova E. Managing flushing and gastrointestinal events associated with delayed-release dimethyl fumarate: experiences of an international panel. Mult Scler Relat Disord. 2014;3:513-9.

12. Dalkey NC, Brown BB, Cochran S. The Delphi method. Santa Monica: Rand Corporation; 1969. 